\title{
ГРУЗИЯ КАК ТРАНСПОРТНЫЙ УЗЕЛ КИТАЙСКОЙ ИНИЦИАТИВЫ «ПОЯС И ПУТЬ»
}

\author{
Корганашвили Л., доктор экономических наук, профессор \\ Грузия, Тбилиси, Тбилисский государственный университет имени И. Джсавахишвили
}

DOI: https://doi.org/10.31435/rsglobal_ejits/30112018/6219

\author{
ARTICLE INFO \\ Received 27 August 2018 \\ Accepted 10 November 2018 \\ Published 30 November 2018

\section{KEYWORDS} \\ Belt and Road Initiative, \\ Silk Road, \\ development, \\ China, \\ Georgia.
} \begin{abstract}
The belt and road initiative (BRI) put forward by the President of the People's Republic of China Xi Jinping in autumn 2013 is one of the priorities of it's modern foreign policy. Within the framework of BRI China has concluded agreements on practical cooperation with many countries, including Georgia. For Georgia, BRI is an opportunity to become a land and sea transport hub between Europe and Asia. The overland route combines the Baku-Tbilisi-Kars railroad with the Yavuz Sultan Selim bridge across the Bosporus Strait. The sea route serves as an gate to Europe through the ports in Batumi, Poti and Anaklia. The work shows the importance of BRI for the formation of Georgia as a transport hub and the benefits that both countries derive from cooperation under this initiative.
\end{abstract}

Citation: Корганашвили Л. (2018) Gruziya kak Transportnii Uzel Kitaiskoi Iniciativi «Poyas i Put». European Journal of Intelligent Transportation Systems. 1(1). doi: 10.31435/rsglobal_ejits/30112018/6219

Copyright: (C) 2018 Корганашвили Л. This is an open-access article distributed under the terms of the Creative Commons Attribution License (CC BY). The use, distribution or reproduction in other forums is permitted, provided the original author(s) or licensor are credited and that the original publication in this journal is cited, in accordance with accepted academic practice. No use, distribution or reproduction is permitted which does not comply with these terms.

Введение. Китайская Народная Республика (КНР) является древней страной, обладающей особой силой в мире. На протяжении многих веков она активно представлялась на мировой арене и сейчас ее значение с каждым годом ростет. В XXI веке ее лозунг - мир, развитие и сотрудничество. Политика мира стратегический выбор Китая, в основе которой лежит традиционная китайская культура. В древних договорах военного искусства рекомендуется побеждать врага без войны - посредством культурного и политического влияния. Используя этот подход, китайцы пытаются отвергнуть распространенный тезис о китайской угрозе, который стал особенно актуальным с 1997 года, когда Китай открыто заявил о своих попытках стать мировым лидером.

На современном этапе КНР проводит открытую политику во всех аспектах, готов развивать сотрудничество со всеми государствами и регионами мира. Несмотря на глобальную цель установления позиции регионального и мирового лидера, Китай соблюдает принципы равенства, взаимного уважения и взаимопонимания крупных и малых государств.

Одним из главных приоритетов современной внешней политики КНР является инициатива создания «Экономического пояса Шелкового пути» и «Морского Шелкового пути XXI века». Эта инициатива была выдвинута президентом КНР Си Цзиньпином осенью 2013 года. В настоящее время она действует под названием «Поясь и путь» (ПиП), а также как «Один пояс, один путь» (ОПОП).

После восстановления независимости (9 апреля 1991 года) стратегической целью Грузии является быстрое развитие страны и повышение уровня жизни населения. Для достижения этой цели Грузия осуществляет либеральную политику и нацелена на сотрудничество со всеми государствами, которые уважают ее национальные интересы. 
Китайская Народная Республика была одной из первых, кто признал независимость Грузии. 9 июня 1992 года было подписано коммюнике об установлении дипломатических отношений между двумя государствами, но традиционная дружба между ними началась со времен «Великого шелкового пути». С 2016 года Грузия участник китайской инициативы «Поясь и путь».

Роль Грузии как маленькой страны в экономическом развитии КНР незначительна. Основываясь на этом экономическое сотрудничестве с Китаем в интересах Грузии, но учитывая ее важную геополитическую позицию, это сотрудничество привлекательно и для Китая. Исходя из этого, у Китая и Грузии есть перспективы тесных экономических отношений, которые подкреплены соответствующей правовой базой.

Цель данной работы показать значение китайской инициативы «Поясь и путь» в формировании Грузии в качестве транспортного узла и те выгоды, которые получать обе стороны в результате сотрудничества в рамках этой инициативы.

Основная часть. Как известно из истории, Великий шелковый путь был проложен во II веке до н. э. Простиравшийся на десять тысяч ли и просуществовавший тысячи лет древний путь накопил в себе особый дух Шелкового пути, в основе которого лежат мир и сотрудничество, открытость и сотрудничество, взаимное обучение, взаимная выгода и всеобщий выигрыш. Дух Великого шелкового пути - это ценнейшее наследие человеческой цивилизации [1]. По географическому и экономическому масштабу Новый шелковый путь намного опережает своего древнего тезку, который представлял собой сухопутный маршрут, используемый исключительно с целью ведения торговли. На суше Новый шелковый путь предполагает строительство новой транспортной инфраструктуры и промышленных коридоров, простирающихся через всю Среднюю Азию на Ближний Восток и в Европу. На море он подразумевает строительство новых портов и создание торговых маршрутов, ведущих через Южно-Китайское море на юг Тихого океана и через Индийский океан в Средиземное море [2]. «Поясь и путь» является самым амбициозным инфраструктурным проектом в современной истории, который создает новую модель взаимодействия стран и способствует открытости мировой экономики, созданию всемирной системы транспортных коридоров. Эта инициатива должна соединить Китай со странами Средней Азии, Европы, Ближнего востока, Африки, Латинской Америки, Океании. В результате этого в орбиту влияния Китая будет вовлечено 4.4 млрд человек - больше половины современного населения мира [3].

Подавляющее большинство проектов международного сотрудничества в рамках «Пояса и пути» направлено на расширение технических возможностей по доставке китайских товаров на ключевые для КНР рынки и обратной транспортировки в Китай сырья и энергоносителей. Эти проекты нацелены на развитие транспортной и логистической инфраструктуры - строительство и модернизация железнодорожных и автомобильных путей сообщения, портов, баз для перевалки и хранения грузов, трубопроводов [4]. С помощью железнодорожных линий перевозки грузов в среднем на 20 дней быстрее, чем морские перевозки. В таблице 1 приведены расстояние и время перевозок грузов между городами Китая и Европы.

Инициатива «Поясь и путь» получила широкую поддержку и позитивный отклик со стороны международного сообщества. В настоящее время более 80 стран и международных организаций подписали с Китаем соглашение о сотрудничестве. Общий объем торговли между Китаем и странами вдоль ОПОП превысил 5 триллионов долларов. За последние пять лет китайские компании инвестировали более 70 миллиардов долларов в страны вдоль ОПОП, создали 75 зон экономического и торгового сотрудничества за рубежом, внесли более 1,6 миллиарда долларов в налогах и сборах принимающей страны и создали 220 тыс. рабочих мест [6]. Грузия, как транспортный узел инициативы «Поясь и путь» привлекательна для Китая по следующим обстоятельстам: 
1. Важное географическое и геополитическое положение в данном регионе. В течение веков здесь пересекались военные и торговые пути. Геополитический фактор является абсолютным преимуществом Грузии, который привлекателен для многих стран-лидеров современного мира, в том числе и для Китая.

Таблица 1. Китайско-европейские грузовые железнодорожные линии [5]

\begin{tabular}{|c|l|l|l|l|}
\hline \multicolumn{1}{|c|}{$\begin{array}{c}\text { Железнодорожные } \\
\text { грузовые линии }\end{array}$} & Год запуска & $\begin{array}{c}\text { Расстояние } \\
\text { (км })\end{array}$ & $\begin{array}{c}\text { Время перевозки } \\
\text { (в днях) }\end{array}$ \\
\hline 1 & Чунцин - Дуйсбург & 2011 & 11179 & 16 \\
\hline 2 & Ухань - Пардубице / Лодзь & 2012 & 10700 & 15 \\
\hline 3 & Сучжоу - Варшава & 2012 & 11200 & 14 \\
\hline 4 & Чанша - Дуйсбург & 2012 & 11808 & 18 \\
\hline 5 & Чжэнчжоу - Гамбург & 2013 & 10245 & 15 \\
\hline 6 & Чэнду - Лодзь & 2013 & 9965 & 14 \\
\hline 7 & Иу - Мадрид & 2014 & 13052 & 21 \\
\hline 8 & Харбин - Гамбург & 2015 & 9820 & $15-17$ \\
\hline 9 & Синин - Антверпен & 2016 & 9838 & 12 \\
\hline 10 & Баодин - Минск & 2016 & 9500 & $12-14$ \\
\hline 11 & Гуанчжоу - Москва & 2016 & 11500 & 15 \\
\hline 12 & Иу - Лондон & 2017 & 12451 & $18-20$ \\
\hline
\end{tabular}

2. Грузия имеет выход в Европу сухопутным и морским путями. Сухопутный маршрут является частью Транскаспийского международного транспортного маршрута (средний коридор). Этот маршрут сочетает железную дорогу Баку-Тбилиси-Карс (БТК) с мостом Явуз Султан Селим через Босфорский пролив. Железная дорога Баку-Тбилиси-Карс - транспортный коридор, соединяющий железнодорожные сети Азербайджана, Грузии и Турции. Она открылась 30 октября 2017 года. Проектируемый грузопоток для данного маршрута составляет 10 млн тонн, с возможным (теоретическим) увеличением до 20 млн тонн [7]. Морской маршрут служить выходом в Европу через Черноморские порты. в Батуми, Поти и Анаклия. В настоящее время в Грузии действуют три порта: Батуми, Поти и Кулеви. В Супсе есть также грузовой терминал с жидкостью. Однако глубина существующих портов недостаточна для приема грузовых кораблей среднего размера или крупных перевозчиков сырой нефти. Для преодоления этого недостатка правительство Грузии приняло решение о строительстве глубоководного порта на берегу Черного моря в Анаклии. Глубина морского порта составляет 20,5 метров (в Батуми - 14 метров, в Поти 8,5 метров). Порт Анаклия сможет принимать корабли большого размера - классов "Панамакс" и "Постпанамакс" грузоподъемностью 50 - 150 тысяч тонн [8]. Ожидается, что новый порт станет одним из основных логистических центров на Южном Кавказе и одним из основных морских шлюзов для Грузии. Потенциальная пропускная способность порта должна достигать 100 миллионов тонн в год [8].

3. Через Грузию проложены нефтепроводы Баку - Тбилиси - Джейхан и Баку Тбилиси - Супса, газопровод Баку - Тбилиси - Эрзерум (его также называют ЮжноКавказским трубопроводом - ЮКТ), она участник проектов TRACECA (Transport Corridor Europe Caucasus Asia) и INOGATE (Interstate Oil and GAs Transportation to Europe). TRACECA - программа международного сотрудничества между Европейским союзом и странами-партнерами по организации транспортного коридора «Европа - Кавказ - Азия». В организационном плане эта международная программа, направленная на укрепление экономических отношений, торговли и транспортного сообщения в регионах Черноморского бассейна, Южного Кавказа и Центральной Азии. Она была создана в 1993 году по идее Евросоюза и состоит из различных проектов, некоторые из которых к началу 2016 года уже завершены [10]. Важную роль в TRACЕСА играет ОАО «Грузинская железная дорога», которая транспортирует как жидкие, так и сухие грузы. Жидкий груз, состоящий из сырой 
нефти и нефтепродуктов, составил 46 \% от общего объема грузовых перевозок в 2016 году, а транзитная отгрузка - около 52\% [11]. INOGATE - программа международного сотрудничества в энергетической сфере между Европейским Союзом, Причерноморскими и Прикаспийскими государствами, а также соседними с ними странами. Программа основана в 1996 году и реализуется от имени Евросоюза [12]. Для указанных трубопроводов и программ уже создана соответствующая инфраструктура, которую можно использовать и для инициативы «Поясь и путь».

4. Грузия имеет Соглашения о свободной торговле как с Евросоюзм, так и с Китаем. Подписанное в мае 2015 года в Пекине Соглашение о свободной торговле вступила в силу 1 января 2018 года [13]. До этого в 2014 году между Евросоюзом и Грузией было подписано Глубокое и всестороннее соглашение о свободной торговле (DCFTA), которое действует с 2016 года [14]. Грузия также подписала Соглашение о свободной торговле с Гонконгом. Это Соглашение было согласовано в 2016 году и имеет несколько стандартных компонентов, а именно: устранение или снижение тарифов, либерализация нетарифных барьеров, гибкость в отношении правил происхождения для содействия двусторонней торговле, процедуры упрощения таможенных процедур, либерализация и поощрение и защита инвестиций; либерализации торговли услугами и механизма урегулирования споров для зоны свободной торговли [15]. В результате этих соглашений Грузия стала связующим звеном между Евросоюзом и Китаем, в том числе в рамках проекта «Поясь и путь». Она также стала привлекательной страной для инвестиций. Как видно из таблицы 2, прямые иностранные инвестиции (ПИИ) в Грузии в 2017 году составили $\$ 1888,8$ млн. По сравнению с 2016 годом они выросли на 20.6\%, а по сравнению с 2013 годом - на 185\%. Прямые инвестиции из Китая в Грузию в 2016 году составили USD 40.3 million, по сравнению с предыдущим годом рост составил 58\%, хотя по сравнению с 2014 годом они снизились почти 5.5 раза. Всего за 5 лет Китай инвестировал в Грузию $\$ 453.9$ миллионов - 5.7\% ПИИ страны (Таблица 2). Для привлечения китайских инвесторов в Грузию создан Банк развития Грузии с капиталом в 1 миллиард долларов США. Учредителями банка являются крупнейшие китайские корпорации: «CEFC China Energy Company Limited» и компания «Eurasian Invest LLC» [16].

Таблица 2. Объем прямых иностранных инвестиций в Грузии (млн \$) [17]

\begin{tabular}{|l|l|l|l|l|l|l|}
\hline & 2013 & 2014 & 2015 & 2016 & 2017 & Total \\
\hline ПИИ в Грузии, всего & $1,020.5$ & $1,817.7$ & $1,665.6$ & $1,565.8$ & $1,888.8$ & $7,958.4$ \\
\hline ПИ из Китая & 101.1 & 220.1 & 66.9 & 25.5 & 40.3 & 453.9 \\
\hline $\begin{array}{l}\text { Доля ПИ из Китая в } \\
\text { общем объеме ПИИ }\end{array}$ & 9.9 & 12.1 & 4.0 & 1.6 & 2.1 & 5.7 \\
\hline
\end{tabular}

Грузия подписала соглашение с Азиатским банком развития (АБР) о финансировании проекта Батумской объездной дороги. Стоимость проекта составляет \$ 315,2 млн., Из которых АБР будет финансировать 108,19 млн. евро [17]. Проект Батумского объездного пути будет завершен в 2022 году. Софинансирование проекта в размере 114 миллионов долларов будет предоставлено Азиатским банком инфраструктурных инвестиций Китая [14]. Проект предусматривает строительство 2-полосной дороги 14,3 км в обход Батуми, а также обслуживание международных и местных дорог общей протяженностью 200 км. Текущая дорога проходит через жилую и туристическую зону Батуми, что создает проблему для транзитных перевозок.

Правительство Грузии планирует проложить 550 километров шоссейных дорог, а также отремонтировать 800 километров существующих путей. Кроме того, будет построено 300 новых мостов и 50 новых туннелей на сумму около 3,5 миллиардов долларов [18]. Все это позволит улучшить инфраструктуру Грузии, как транспортного узла инициативы «Поясь и путь».

Грузия имеет хорошие транспортные возможности, однако они мало освоены. По индексу эффективности логистики Всемирного Банка Грузия в 2018 году занимает 124-ое место, что на 8 позиций ниже индекса 2016 года (116-ое место). среди 160 стран в 2014 году 
она была на 116-ом месте среди 160 стран, а в 2012 году - на и на 40 позиций ухудшила положение по сравнению с 2012 годом. Соответственно эффективность работы цепей поставок в международной торговле уменьшается, что указывает на снижение легкости осуществления поставок товаров и состояние торговой логистики на национальном и международном уровне.

В последние годы двусторонние отношения между Грузией и Китаем развиваются быстрыми темпами и имеют положительные результаты. Грузия позитивно смотрит на инициативу «Поясь и путь» и хочет укрепить сотрудничество с Китаем в различных областях.

Заключение. Инициатива «Поясь и путь» способствует экономическму развтию многих стран. Грузия ожидает, что эта инициатива приведет к увеличению транзита и заметному подъему национальной экономике. В целом инициатива «Поясь и путь полезна как для Грузии, так и для Китая. В этом контексте правительства обеих стран должны приложит все усилия для дальнейшего углубления их сотрудничества. У Грузии есть шанс стать связующим звеном между Европой и Азией и извлечь выгоду из своего географического и геополитического положения.

\section{ЛИТЕРАТУРА}

1. «Один пояс, один путь»: полный текст речи Си Цзиньпина https://inosmi.ru/politic/20170519/239391693.html

2. Miller Tom (2017). China's clout has few limits. Shouldn't we be worried about its new Silk Road? https://www.theguardian.com/commentisfree/2017/sep/04/china-economic-clout-new-silk-road

3. Китайские инвестиции в Грузию содействуют реализации инициативы "Пояс и путь". https://dknews.kz/silk-road/54080-kitajskie-investitsii-v-gruziyu-sodejstvuyut-realizatsii-initsiativy-poyasi-put.html

4. Пояс и путь. Китайский ответ на американский вызов. https:/www.fondsk.ru/news/2017/05/13/pojas-iput-kitajskij-otvet-na-amerikanskiy-vyzov-43975.html

5. Initiatives of the "New Silk Road" Achievements and Challenges. Edited by Duško Dimitrijević and Huang Ping. Belgrad. 2017. http://www.eppi-online.com/2017/06/08/silk-road-with-detours/, http://16plus1thinktank.com/u/cms/cepzh/201712/13095430sus8.pdf

6. Внедрение дипломатии великой державы с китайской спецификой и совместное строительство глобального партнерства. http://avesta.tj/2018/08/10/vnedrenie-diplomatii-velikoj-derzhavy-s-kitajskojspetsifikoj-i-sovmestnoe-stroitelstvo-globalnogo-partnerstva/

7. Железная дорога Баку-Тбилиси-Карс. https://ru.wikipedia.org/wiki/\%D0\%96\%D0\%B5\%D0\%BB\%D0\%B5\%D0\%B7\%D0\%BD\%D0\%B0\%D1\% $8 \mathrm{~F} \% \mathrm{D} 0 \% \mathrm{~B} 4 \% \mathrm{D} 0 \% \mathrm{BE} \% \mathrm{D} 1 \% 80 \% \mathrm{D} 0 \% \mathrm{BE} \% \mathrm{D} 0 \% \mathrm{~B} 3 \% \mathrm{D} 0 \% \mathrm{~B} 0 \% \mathrm{D} 0 \% 91 \% \mathrm{D} 0 \% \mathrm{~B} 0 \% \mathrm{D} 0 \% \mathrm{BA} \% \mathrm{D} 1 \% 83$ $\% \overline{\mathrm{E}} 2 \% 80 \% 94 \quad \% \mathrm{D} 0 \% \mathrm{~A} 2 \% \mathrm{D} 0 \% \mathrm{~B} 1 \% \mathrm{D} 0 \% \mathrm{~B} 8 \% \mathrm{D} 0 \% \mathrm{BB} \% \mathrm{D} 0 \% \mathrm{~B} 8 \% \mathrm{D} 1 \% 81 \% \mathrm{D} 0 \% \mathrm{~B} 8 \_\% \mathrm{E} 2 \% 80 \% 94 \_\% \mathrm{D} 0$ $\% 9 \mathrm{~A} \% \mathrm{D} 0 \% \mathrm{~B} 0 \% \mathrm{D} 1 \% 80 \% \mathrm{D} 1 \% 81$

8. Международный морской порт Анаклия. http://anaklia.travel/en/news/novosti-anaklii/miezhdunarodnyimorskoi-port-anakliia.html

9. China deepens its presence in Georgia via its "One Road, One Belt" initiative. By John C. K. Daly http://www.cacianalyst.org/publications/analytical-articles/item/13413-china-deepens-its-presence-in-georgia-

10. TRACECA. http://www.traceca-org.org/ru/traseka/, https://ru.wikipedia.org/wiki/\%D0\%A2\%D0\%A0\%D0\%90\%D0\%A1\%D0\%95\%D0\%9A\%D0\%90

11. Georgian Railway. Annual repport 2016. http://www.railway.ge/files/q12012/annual_report_2016.pdf

12. INOGATE. http://www.inogate.org/, https://ru.wikipedia.org/wiki/INOGATE

13. China-Georgia FTA. http://fta.mofcom.gov.cn/list/chinageorgiaen/chinageorgiaennews/1/encateinfo.html

14. Глубокое и всестороннее соглашение о свободной торговле (DCFTA) http://investingeorgia.org/ru/georgia/free-trade-regimes/ftas/ftas-first

15. Georgia-Hong Kong Free Trade Agreement Signed http://georgiatoday.ge/news/11029/Georgia-HongKong-Free-Trade-Agreement-Signed

16. Китайский банк в Грузии будет на 100\% коммерческим http://bizzone.info/banking/2017/1496167086.php

17. Geostat. Foreign Direct Investments. http://geostat.ge/cms/site_images/_files/english/bop/ucxouri\%20investiciebi\%2015.08\%20(eng)_2018.pdf

18. «Один пояс, один путь»: что светит Грузии? http://www.inosmi.info/odin-poyas-odin-put-chto-svetitgruzii.html

19. Within initiative "One belt - One road" China will assist Georgia to develop transcaspain international transport http://dspace.nplg.gov.ge/bitstream/1234/275199/1/Foreign_Business_In_Georgia_Summer_2018.pdf

20. Trade Logistics in the Global Economy. https://openknowledge.worldbank.org/bitstream/handle/10986/29971/LPI2018.pdf 